\title{
A SENSITIVE SEQUENTIAL INJECTION ANALYSIS (SIA) DETERMINATION OF MEMANTINE HYDROCHLORIDE USING LUMINOL-HYDROGEN PEROXIDE INDUCED CHEMILUMINESCENCE DETECTION
}

\author{
NAWAL A. ALARFAJ, MAHA F. EL-TOHAMY* \\ Department of Chemistry, College of Science, King Saud University, P.O. Box 22452, Riyadh 11495, Saudi Arabia
}

\begin{abstract}
A fully automated sequential injection analysis (SIA) method for chemiluminescence (CL) determination of Al-zheimer's drug memantine hydrochloride was developed and presented. The employing of SIA injection analysis facilitates fluidic handling and lowering the consumption of sample and reagents. The basic CL reaction was based on the emission of CL radiation due to the reaction of luminol with hydrogen peroxide in basic medium. The CL emission has been monitored using FIAlab system. The optimum conditions and characterizations were optimized using a computer-aided simplex method. Under the optimal conditions the linear calibration graph was obtained within the range of 0.0001-1.0 $\mu \mathrm{g} \mathrm{mL} \mathrm{L}^{-1},(\mathrm{r}=0.9996)$ with detection limit of $3.3 \times 10^{-5} \mu \mathrm{g} \mathrm{mL} \mathrm{m}^{-1}$ along with relative standard deviation $1.8 \%(\mathrm{n})$. The flow rates were $120 \mu \mathrm{L} \mathrm{s}^{-1}$, for the aspiration into the holding coil and $80 \mu \mathrm{L} \mathrm{s}^{-1}$ for detection. The sample frequency throughput was 103 $\mathrm{h}^{-1}$. The proposed CL method was successfully applied for determination of the tested drug in pure form and its pharmaceutical formulations. The interference of some common additive compounds such as glucose, lactose, starch, talc and magnesium stearate was investigated. No interference was recorded. The obtained SIA results were statistically compared with those obtained from a reported method and did not show any significant difference.
\end{abstract}

Keywords: Sequential injection analysis; Chemiluminescence determination; Memantine hydrochloride; Pharmaceutical formulations

\section{INTRODUCTION}

Memantine hydrochloride (Figure 1) chemically known as 1-amino-3,5 dimethyladamantane hydrochloride. Memantine is used to treat the symptoms of Alzheimer's disease. It is in a class of medications called $N$-Methyl- $D$ aspartate receptor (NMDA) receptor antagonists. This medication works by decreasing abnormal excitement in the brain. Memantine can help people with Alzheimer's disease to think more clearly and perform daily activities more easily. Memantine may also be prescribed to treat other medical conditions [1]. Because of its important and intensive medicinal uses several methods have been proposed for its determination in pharmaceutical formulations and biological fluids. These mainly include high performance liquid chromatography [2-4], liquid chromatography coupled with mass spectrometry $[5,6]$, gas chromatography $[7,8]$, spectrophotometry [9-11] and spectrofluorimetry [11].

The use of SIA-injection chemiluminescence seems to be quite important during recent years. This can be attributed to the fair sensitivity of such analytical technique that can be employed in the determination of different compounds in various fields.

In the present study a simple, accurate and reliable SIA-injection CL system was adopted for the determination of memantine hydrochloride in pure form and its dosage forms. The utilization of luminol-hydrogen peroxide system together with SIA injection allows minimizing the consumption of reagents and samples. Method validation for the proposed SIA-CL method for the determination of memantine hydrochloride was carried out according to ICH guidelines [12].

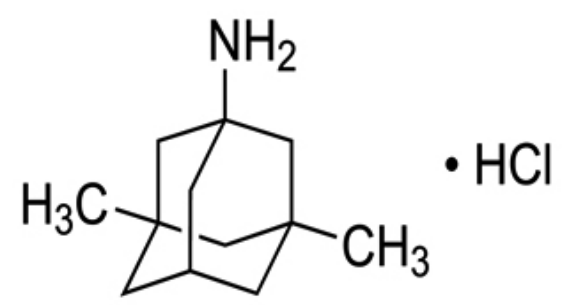

Figure 1: Chemical structure of memantine hydrochloride

\section{EXPERIMENTAL}

\subsection{Instrumentation}

SIA system (FIAlab-3500 instrument, USA) comprised of a CAVRO XL 3000 syringe pump volume $2.5 \mathrm{~mL}$ (Cavro Scientific Instrument Int., USA) and Vici Valco Cheminer RT ${ }^{\circledR}$ 125-0718 eight-port manifolds. Fluorimetric/ Chemiluminescence detector (UIV lamp switched off) equipped with a lab- made CL module with spiral geometry; the photomultiplier tube voltage was $320 \mathrm{~V}$. Autosampler model ALM 3200. The SIA system involved a holding coil (length $70 \mathrm{~cm}$, i.d. $0.8 \mathrm{~mm}$, PTFE tubing volume $1.2 \mathrm{~mL}$ ). The same tubing was spirally coiled on a $52 \mathrm{~mm} \times 52 \mathrm{~mm}$ Perspex plate, which substituted the secondary filter in the fluorimeter; this CL module had a central inlet, peripheral outlet and the diameter of the spiral was $24 \mathrm{~mm}$. The SIA unit was PC controlled and data acquisition was performed with (FIAlab for windows version 5.9.321) software. The solution stability monitoring and UV spectrophotometry was performed on an UV-Visible Spectrophotometer Ultrospec (model 2100 pro).

2.2. Reagents

Distilled water and analytical grade reagents were used throughout the work. Pure grade memantine hydrochloride was kindly supplied from Adwia Co. Egypt. 5.0 $\times 10^{-4} \mathrm{~mol} \mathrm{~L}^{-1}$ luminol (Sigma Chemical Co.) stock solution was prepared in $100 \mathrm{~mL}$ of $1.0 \times 10^{-2} \mathrm{~mol} \mathrm{~L}^{-1}$ sodium hydroxide (WINLAB). Hydrogen peroxide $30 \%$ (WINLAB) was used to prepare $1.0 \times 10^{-3} \mathrm{~mol} \mathrm{~L}^{-1}$ by appreciated dilution using distilled water. Cationic surfactants such as cetylprydenium chloride $(\mathrm{CPCl})$, cetyltrimethylammnium bromide (CTAB), non-ionic surfactants such as glycerol, tween-80 and triton-X 100 and anionic surfactants such as sodium lurayl sulphate (SDS) and 1,2-naphoqinon-4sulphonate (NQS) were purchased from (Sigma Aldrich, Germany). The pharmaceutical preparation (Ravemantine ${ }^{\circledR} 10 \mathrm{mg} /$ tablet, EVA, Pharm. Egypt) was purchased from local drug stores.

2.3. Standard drug solution

A stock standard memantine hydrochloride solution $100 \mu \mathrm{g} \mathrm{mL}^{-1}$ was prepared by dissolving $10 \mathrm{mg}$ of pure drug in $100 \mathrm{~mL}$ distilled water. Working solutions were prepared daily by appropriate dilution. The employed working solutions were in the range of $0.0001-1.0 \mu \mathrm{g} \mathrm{mL}^{-1}$.

\subsection{Manifold and procedures}

The following procedure was carried out for the determination of memantine hydrochloride. All experiments were computer controlled to ensure timing of syringe pump and valve movements. The schematic diagram of SIA-CL system as shown in Figure 2 was employed for automated aspiration of the appropriate defined volumes of standard and test solutions of analyte and reagents. Prim-port program was used first to fill in the lines connected with the test solution and reagents. The sequence of the aspirated sample and reagents was automatically controlled. Mixture of $80 \mu \mathrm{L}$ luminol $5.0 \times 10^{-4} \mathrm{~mol}$ $\mathrm{L}^{-1}, 60 \mu \mathrm{L}$ sample solution and $80 \mu \mathrm{L}$ hydrogen peroxide $1.0 \times 10^{-3} \mathrm{~mol} \mathrm{~L}^{-1}$ was aspirated into the holding coil through the eight-way injection valve at a flow rate $120 \mu \mathrm{L} \mathrm{s}^{-1}$ and then the mixed solution was flushed continuously into the flowthrough cell located in front of detection cell of the photomultiplier tube (PMT). The resulting peak heights were calculated automatically by FIAlab ${ }^{\mathbb{E}}$ supported software version 9.5.321. The luminescing zone was dispensing into detector using pre-programmed measuring cycles. Each measuring cycle was carried out in triplicate and the mean peak heights were used in the evaluation of the experiments. All measurements were carried out at ambient temperature 
$25 \pm 1^{\circ} \mathrm{C}$. During the SIA-CL detection of memantine hydrochloride about 1000 $\mu \mathrm{L}$ distilled water was used as carrier for delivering sample and reagents zones into the flow cell for measuring the CL signal. The obtained data was stored in the $\mathrm{PC}$ for subsequent processing.

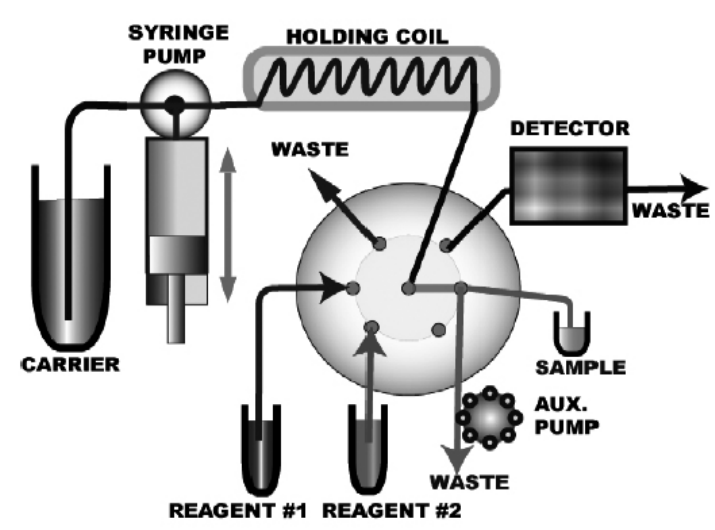

Figure 2: Schematic diagram of SIA injection system for chemiluminescence determination of memantine hydrochloride; carrier stream (water); reagent 1 (luminol 5.0x $10^{-4} \mathrm{~mol} \mathrm{~L}^{-1}$ ); reagent 2 (hydrogen peroxide $1.0 \times 10^{-3} \mathrm{~mol} \mathrm{~L}^{-1}$ ); sample (memantine hydrochloride $0.1 \mu \mathrm{g} \mathrm{mL}^{-1}$ )

\subsection{Calibration}

Under the optimum conditions the calibration curve for determination of memantine hydrochloride was obtained. The graph related the CL intensity vs. the concentration of tested drug solutions was plotted at 12 experimental points. The mean peak heights were obtained after triplicate sample aspiration. Conventional linear regression was utilized for fitting the curve.

2.6. Analytical applications

2.6.1. Determination of memantine hydrochloride in ravemantine $e^{\circledR}$ tablets

To determine memantine hydrochloride in its dosage form (Ravemantine ${ }^{\mathbb{E}}$ $10 \mathrm{mg} /$ tablet) twenty tablets were finely powdered and weighed. An amount of powder equivalent to $10 \mathrm{mg}$ memantine hydrochloride was dissolved in distilled water and then sonicated for $10 \mathrm{~min}$. The sonicated solution was filtered using membrane filter (pore size $5.0 \mu \mathrm{m}$ ) and complete to $100-\mathrm{mL}$. The working solutions were prepared by serial dilutions in the range of $0.001-1.0 \mu \mathrm{g} \mathrm{mL}$ 1. The proposed SIA-CL method was employed to determine the investigated drug in each concentration. The mean \% recoveries were calculated using calibration graph.

2.6.2. Content uniformity assay of tablets

The content uniformity assay of memantine hydrochloride (Ravemantine ${ }^{\mathbb{R}}$ $10 \mathrm{mg} /$ tablet) was carried out using the proposed SIA-CL detection. Ten individual tablets were dissolved separately in $100 \mathrm{~mL}$ distilled water. The prepared solutions were sonicated for $10 \mathrm{~min}$ then filtered through membrane filter (pore size $0.5 \mu \mathrm{m}$ ). $1.0 \mathrm{~mL}$ of the previously filtered solution was transferred into a conical flask and complete to $100 \mathrm{~mL}$ with distilled water to obtain a test solution containing $1.0 \mu \mathrm{g} \mathrm{mL} \mathrm{m}^{-1}$ of memantine hydrochloride. The SIA-CL method was employed to determine the content uniformity assay of the tablets using the calibration graph.

\section{RESULTS AND DISCUSSION}

\subsection{Optimization studies}

3.1.1. Selection of hydrogen peroxide as oxidizing agent

To select the suitable oxidizing agent various oxidants were carefully investigated including potassium ferricyanide, potassium permanganate, potassium periodate, hydrogen peroxide and Ce (IV). It was seen that no CL signal was recorded on using all these oxidizing agents. While, on using luminol with hydrogen peroxide exhibits a CL signal in the presence of alkaline medium. Therefore, the proposed procedure was based on the enhancement effect of memantine hydrochloride on the luminol-hydrogen peroxide- CL signal and the effect of luminol and hydrogen peroxide concentrations was further investigated and optimized.

\subsubsection{Effect of luminol and hydrogen peroxide concentrations}

The influence of luminol and hydrogen peroxide concentrations on the $\mathrm{CL}$ signal was investigated using $1.0 \times 10^{-5}-1 . \times 10^{-1} \mathrm{~mol} \mathrm{~L}^{-1}$ for both reagents. As shown in Figure 3, it was found that the CL intensity showed significant increase at $5.0 \times 10^{-4}$ and $1.0 \times 10^{-3} \mathrm{~mol} \mathrm{~L}^{-1}$ for luminol and hydrogen peroxide, respectively. Therefore, these concentrations are chosen for the subsequent experimental analysis.

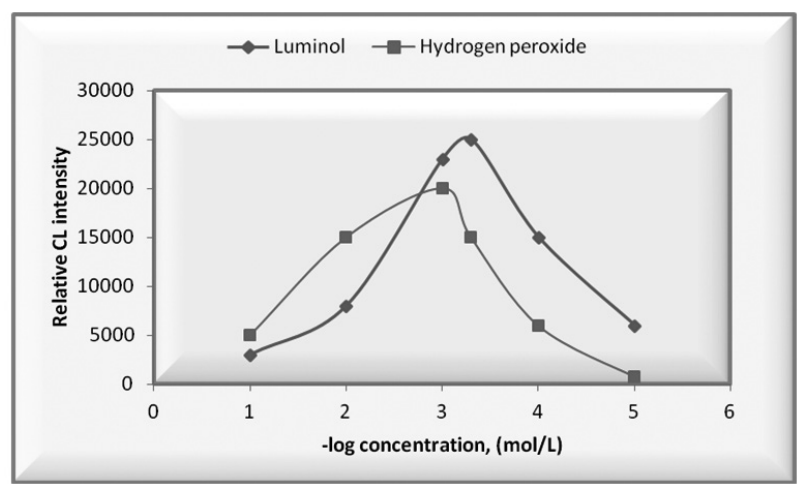

Figure 3: Effect of luminol and hydrogen peroxide concentrations, for luminol concentration, (memantine hydrochloride $0.1 \mu \mathrm{g} \mathrm{mL} L^{-1}$ and hydrogen peroxide $1 \times 10^{-3} \mathrm{~mol} \mathrm{~L}^{-1}$ ) and for hydrogen peroxide concentration (memantine hydrochloride $0.1 \mu \mathrm{g} \mathrm{mL}^{-1}$ and luminol $5.0 \times 10^{-4} \mathrm{~mol} \mathrm{~L}^{-1}$ )

\subsubsection{Optimization of alkaline medium}

In order to select and investigate the suitable alkaline medium as a solvent for luminol, three kinds of alkaline media including ammonium hydroxide, sodium bicarbonate and sodium hydroxide in the range $1.0 \times 10^{-3}-1.0 \times 10^{-1}$ mol L-1 were examined. As shown in Figure 4, it was found that the use of $1.0 \times 10^{-2} \mathrm{~mol} \mathrm{~L}^{-1}$ sodium hydroxide gave a sharp CL signal while in the cases of ammonium hydroxide and sodium bicarbonate a significant decrease in CL signal was obtained. Therefore, $1.0 \times 10^{-2} \mathrm{~mol} \mathrm{~L}^{-1}$ sodium hydroxide was used in the proposed method as a solvent for luminol.

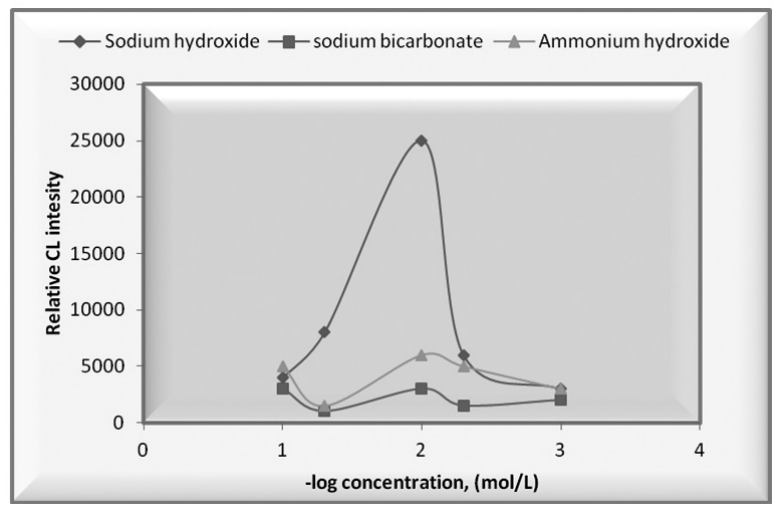

Figure 4: Effect of sodium hydroxide and sodium bicarbonate concentration on CL intensity system (memantine hydrochloride $0.1 \mu \mathrm{g} \mathrm{mL}^{-1}$, hydrogen peroxide $1 \times 10^{-3} \mathrm{~mol} \mathrm{~L}^{-1}$ and luminol $5.0 \times 10^{-4} \mathrm{~mol} \mathrm{~L}^{-1}$ )

\subsubsection{Optimization of aspirated volumes of sample and reagents}

The aspirated volume of sample and reagents was considered as very critical parameter which should be governed and carefully optimized. To optimize the aspirated volume of sample and reagents computer-aided simplex method was used. The proposed method was carried out by varying the volume of sample and CL reagents solutions. As shown in Figure 5a, it was clear that for sample, the CL intensity increased with increasing sample zone volume up to $60 \mu \mathrm{L}$ and then kept unchangable. This may be attributed to adjacent samplereagent zones and disperse to each other to form the CL reaction. Moreover for $\mathrm{CL}$ reagents the optimum aspirated volume was $80 \mu \mathrm{L}$. The time was extended to $35 \mathrm{~s}$ for complete flushing through the holding cell with carrier in between analysis cycles. Also the influence effect of the flow rate on CL intensity was investigated in the range of $10-150 \mu \mathrm{L} \mathrm{s}^{-1}$. It was noticed that the CL intensity was increased with the increase of flow rates. The optimum flow rate was found to be $120 \mu \mathrm{L} \mathrm{s}^{-1}$ and was used for further studies (Figure 5b). 


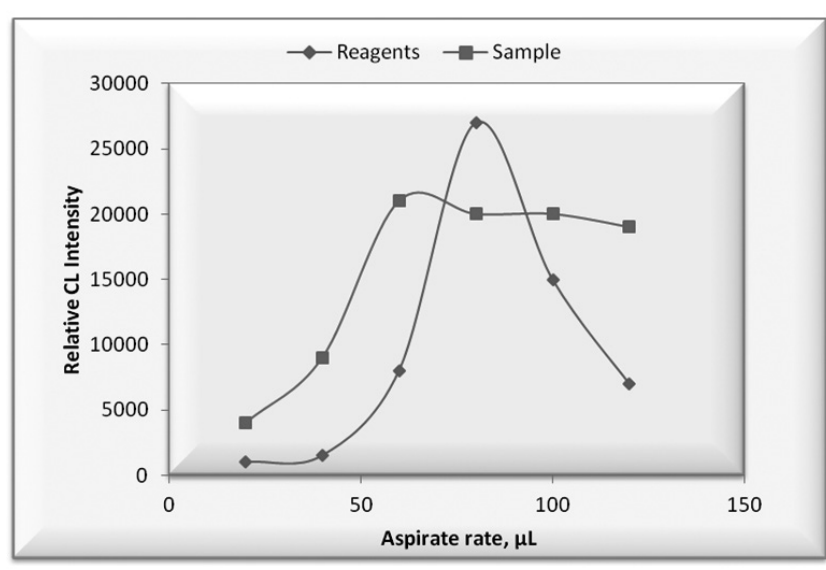

Figure 5a: The influence of aspirated volumes of memantine hydrochloride and reagents $(10-150 \mu \mathrm{L})$ on the relative $\mathrm{CL}$ intensity. Conditions: memantine hydrochloride $0.1 \mu \mathrm{g} \mathrm{mL}^{-1}$; hydrogen peroxide $1.0 \times 10^{-3} \mathrm{~mol} \mathrm{~L}^{-1}$ and luminol $5.0 \times 10^{-4} \mathrm{~mol} \mathrm{~L}^{-1}$

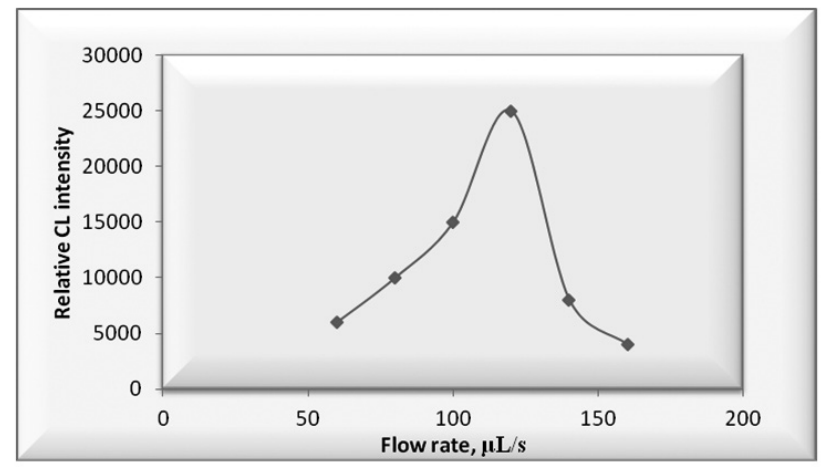

Figure 5b: The influence of flow rate on the relative CL intensity. Conditions; memantine hydrochloride $0.1 \mu \mathrm{g} \mathrm{mL}^{-1} ; 80 \mu \mathrm{L}$ hydrogen peroxide $1.0 \times 10^{-3} \mathrm{~mol} \mathrm{~L}^{-1} ; 80 \mu \mathrm{L}$ luminol $1.0 \times 10^{-4} \mathrm{~mol} \mathrm{~L}^{-1}$ and $\mathrm{pH} 10$

\subsection{SIA control program}

In order to perform all calibration measurements and experimental analysis of memantine hydrochloride, SIA control program was utilized. The utilized program also used to carry out the assay of memantine hydrochloride in its pharmaceutical dosage forms. The typical sequence of particular steps of program is presented in Table 1. It was clear that the single cycle takes about $35 \mathrm{~s}$ therefore, the sample throughput of $103 \mathrm{~h}^{-1}$ can be recorded.

\subsection{Characterizations}

SIA-CL luminol-hydrogen peroxide system was applied for the determination of memantine hydrochloride. The presented results in Table 2, clarified that the measurable linear concentration range was $0.0001-1.0 \mu \mathrm{g} \mathrm{mL}^{-1}$, $(\mathrm{r}=0.9996)$ with lower limit of detection of $3.3 \times 10^{-5} \mu \mathrm{g} \mathrm{mL}^{-1}$ and quantification limit of $1.0 \times 10^{-4} \mu \mathrm{g} \mathrm{mL}^{-1}$. The regression parameters were calculated from the calibration graph, the reproducibility of the proposed method was tested using twelve drug test solutions and the relative standard deviations were less than $5 \%$ indicating that the proposed method was suitable for routine analysis of the investigated drug.

3.4. Effect of foreign substances

In order to determine memantine hydrochloride in its pharmaceutical dosage form, the interference of some common ions and excipients was investigated. To evaluate the interferences a test solution of $0.1 \mu \mathrm{g} \mathrm{mL} \mathrm{L}^{-1}$ of memantine hydrochloride was treated with appropriate foreign substance to contain $\approx 1.0 \mathrm{mg} \mathrm{mL}^{-1}$. The mean peak heights were compared with those obtained with pure $0.1 \mu \mathrm{g} \mathrm{mL} \mathrm{m}^{-1}$ analyte solution. The results of tolerable concentration level for interference at $5 \%$ level were listed in Table 3. It was clear that no interferences have been seen in the determination of memantine hydrochloride in its pharmaceutical dosage forms.

3.5. Effect of surfactants

To study the effect of surfactants on SIA-CL luminol-hydrogen peroxide system for determination of memantine hydrochloride different kinds of surfactants were investigated. Cationic surfactants such as cetylprydenium chloride $(\mathrm{CPCl})$, cetyltrimethylammonium bromide $(\mathrm{CTAB})$, non-ionic surfactants such as glycerol, tween-80 and triton-X 100 and anionic surfactants such as sodium dodecyl sulphate (SDS) were tested. $0.1 \mu \mathrm{g} \mathrm{mL} \mathrm{L}^{-1}$ of the investigated drug memantine hydrochloride was treated with appropriate amount of surfactant $\approx 1.0 \mathrm{mg}$ and the SIA-CL method was proposed for detection. The CL signal was recorded for each surfactant and the peak heights of the signals were compared with those of pure memantine hydrochloride 0.1 $\mu \mathrm{g} \mathrm{mL}^{-1}$. As cleared in Figure 6, no enhancement effect was obtained.

Table 1: The control program of SIA-chemiluminescence detection of memantine hydrochloride with luminol and hydrogen peroxide system

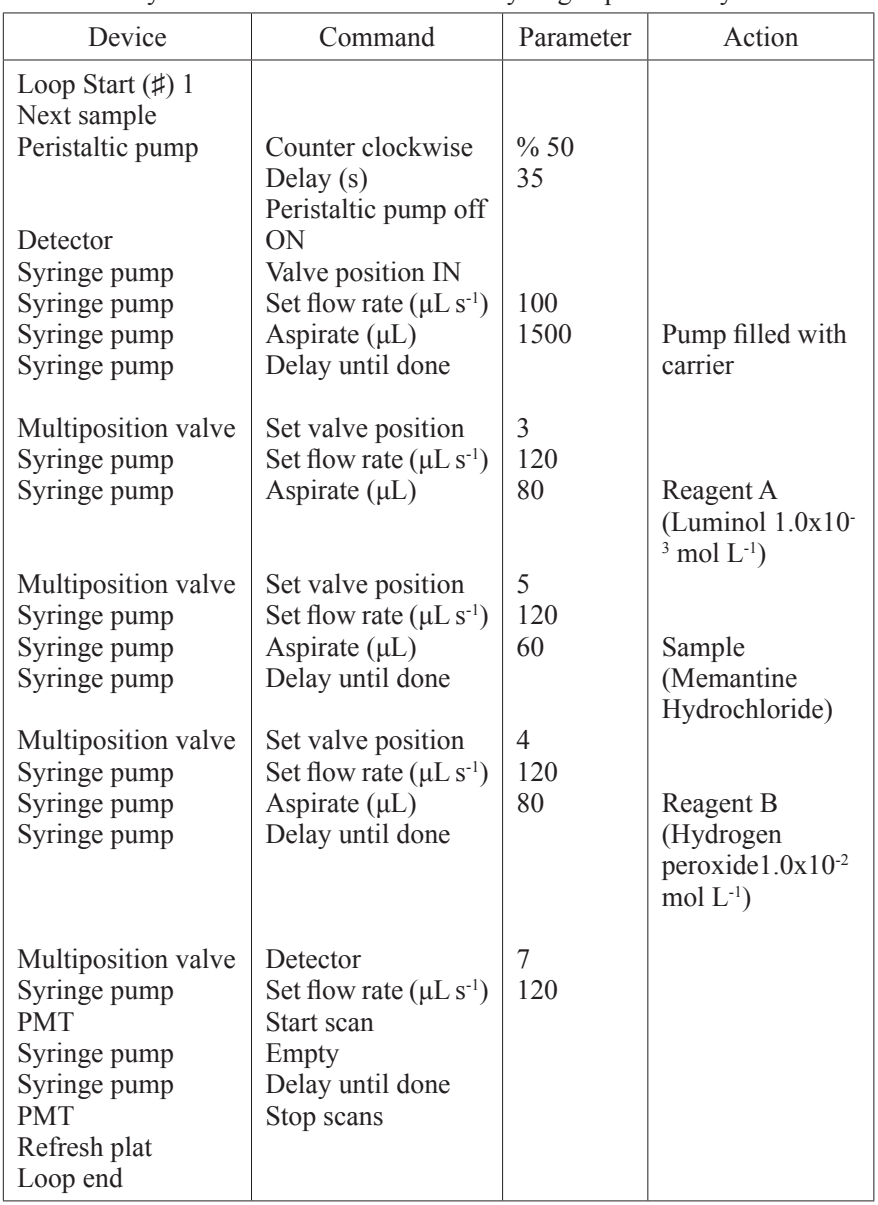

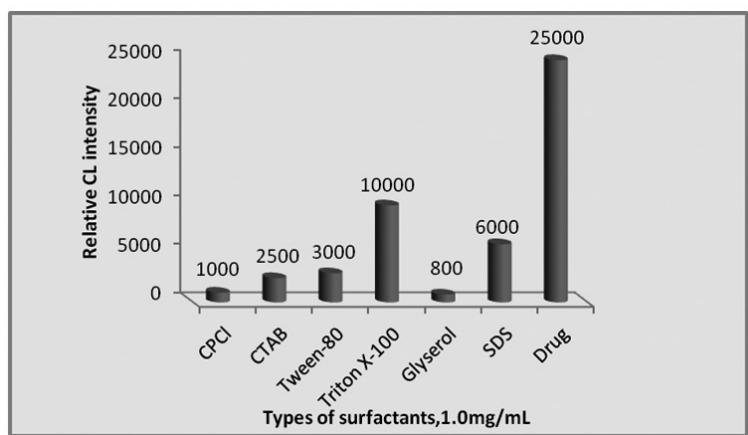

Figure 6: Effect of surfactants $\left(1.0 \mathrm{mg} \mathrm{mL}^{-1}\right)$ on SIA-CL system (memantine hydrochloride $0.1 \mu \mathrm{g} \mathrm{mL}^{-1}$, hydrogen peroxide $1 \times 10^{-3} \mathrm{~mol} \mathrm{~L}^{-1}$ and luminol $5.0 \times 10^{-4} \mathrm{~mol} \mathrm{~L}^{-1}$ )

3.6. Analytical applications

The proposed SIA-injection CL was used for the determination of memantine hydrochloride in its dosage forms. The obtained results were 
presented in Table 4 and statistically compared by Student's t-test [13] with those obtained from the reported spectrophotometric method [9]. The results did not reveal any significant difference between them. The content uniformity assay for memantine hydrochloride tablets was investigated and the results were presented as the mean $\%$ recoveries and standard deviation $(99.24 \pm 1.6)$. To improve further accuracy and precision for the proposed method the results in terms of linear concentration range and lower limit of detection obtained from the determination of the proposed method were compared with those recorded in previously reported methods as summarized in Table 5.

\subsection{Method validation}

Method validation was carried out with respect to linearity, lower limit of detection, quantification limit, accuracy, precision, and robustness according to ICH guidelines [12].

3.7.1. Linearity

The proposed SIA-CL method for determination of memantine hydrochloride using luminol-hydrogen peroxide system was successfully applied for evaluation of the linear concentration range. Visual inspection of a plot of signals as a function of memantine hydrochloride concentrations was used. Twelve standard solutions in the concentration range of 0.0001-10.0 $\mu \mathrm{g}$ $\mathrm{mL}^{-1}$ were subjected to SIA-CL detection. The regression line was calculated using least square statistical method. The results obtained clarified that the proposed SIA-CL method exhibits a linear concentration range at $0.0001-1.0$ $\mu \mathrm{g} \mathrm{mL} \mathrm{m}^{-1}$.

Table 2: Tolerable concentration level of interferents to $0.1 \mu \mathrm{g} \mathrm{mL} L^{-1}$ memantine hydrochloride

\begin{tabular}{|l|c|}
\hline \multicolumn{1}{|c|}{ Interferents } & $\begin{array}{c}\text { Tolerable } \\
\text { level } \\
\mu \mathrm{g} \mathrm{mL}\end{array}$ \\
\hline $\begin{array}{l}\mathrm{Na}^{-1}, \mathrm{~K}^{+}, \mathrm{Mg}^{2+}, \mathrm{Cl}^{-}, \mathrm{NO}_{3}{ }_{3}, \mathrm{NH}_{4}^{+} \text {and } \mathrm{SO}_{4}^{2-} \\
\mathrm{Glucose}^{2-} \text { sucrose, lactose, Talc, Starch }\end{array}$ & $>100$ \\
$\begin{array}{l}\text { Uric acid, magnesium stearate, citric acid, oxalic acid } \\
\text { Adrenaline, dopamine, cystine, histamine, tyrosine, } \\
\text { glucosamine }\end{array}$ & 75 \\
$\mathrm{Cd}^{2+}, \mathrm{Co}^{2+}, \mathrm{Fe}^{2+}, \mathrm{Fe}^{3+}, \mathrm{Mn}^{2+}, \mathrm{Ni}^{2+}$, and $\mathrm{Cu}^{2+}$ & 25 \\
\hline
\end{tabular}

Table 3: Performance data obtained from the determination of memantine hydrochloride using luminol and hydrogen peroxide system

\begin{tabular}{|l|c|}
\hline \multicolumn{1}{|c|}{ Analytical characteristics } & Obtained results \\
\hline Linear range $\mu \mathrm{g} \mathrm{mL}^{-1}$ & $0.0001-1.0$ \\
Detection limit $\mu \mathrm{g} \mathrm{mL}^{-1}$ & $3.3 \times 10^{-5}$ \\
Quantification limit $\mu \mathrm{g} \mathrm{mL}^{-1}$ & $1.0 \times 10^{-4}$ \\
Intercept on the ordinate & 2095.2 \\
Slope & 100.5 \\
\%RSD for $0.1 \mu \mathrm{g} \mathrm{mL}^{-1}(\mathrm{n}=12)$ & $1.8 \%$ \\
Correlation coefficient, $\mathrm{r}$ & 0.9996 \\
\hline
\end{tabular}

\subsubsection{Lower limit of detection $L O D$}

In order to evaluate the lower limit of detection of the proposed SIA-CL methodfor determination of memantine hydrochloride signal-to-noise ratio was performed. The lower limit of detection was calculated by $\mathrm{S} / \mathrm{N}=3$ as the concentration of memantine hydrochloride CL signal exceeds three times that of blank signal. The recorded signals showed lower limit of detection of $3.3 \times 10$ ${ }^{5} \mu \mathrm{g} \mathrm{mL}^{-1}$.

3.7.3. Quantification limit

The proposed SIA-CL method for determination of memantine hydrochloride was employed for the determination of quantification limit of the investigated drug. Signal-to-noise ratio was performed for such evaluation. The obtained result was $1.0 \times 10^{-4} \mu \mathrm{gL}^{-1}$ using 10:1 signal-to noise ratio.

3.7.4. Accuracy

The accuracy of the proposed SIA-CL method was carried out by investigating the tested drug in its placebo sample magnesium stearate using standard addition method.
Table 4: Determination of memantine hydrochloride using SIA-injection $\mathrm{CL}$ detection in pure form and dosage forms

\begin{tabular}{|c|c|c|c|c|}
\hline Sample & $\begin{array}{c}\text { Taken } \\
\mu \mathrm{g} \mathrm{mL}^{-1}\end{array}$ & Found & $\begin{array}{c}\% \\
\text { Recovery }\end{array}$ & \\
\hline Pure solution & $\begin{array}{c}1.010^{-4} \\
5.010^{-4} \\
1.010^{-3} \\
5.010^{-3} \\
1.010^{-2} \\
1.010^{-1} \\
1.0\end{array}$ & $\begin{array}{c}9.99 \times 10^{-5} \\
4.99 \times 10^{-4} \\
9.99 \times 10^{-4} \\
4.92 \times 10^{-3} \\
9.91 \times 10^{-3} \\
1.00 \times 10^{-1} \\
0.9996\end{array}$ & $\begin{array}{c}99.90 \\
99.80 \\
99.85 \\
98.40 \\
99.06 \\
100.00 \\
99.96\end{array}$ & $\begin{array}{c}\text { Reported } \\
\text { method } \\
\text { [9] }\end{array}$ \\
\hline $\begin{array}{l}\% \text { Mean } \pm \mathrm{SD} \\
\mathrm{n} \\
\text { Variance } \\
\% \mathrm{SE} \\
\% \mathrm{RSD} \\
\text { t-test } \\
\text { F-test }\end{array}$ & \multicolumn{3}{|c|}{$\begin{array}{c}99.57 \pm 0.61 \\
7 \\
0.37 \\
0.23 \\
0.61 \\
0.685(2.201)^{*} \\
1.73(4.39)^{*}\end{array}$} & $\begin{array}{c}99.84 \pm 0.83 \\
6 \\
0.64 \\
0.32 \\
0.83\end{array}$ \\
\hline $\begin{array}{l}\text { Ravemantine } \\
10 \mathrm{mg} / \text { tablets }\end{array}$ & $\begin{array}{c}1.010^{-3} \\
5.010^{-3} \\
1.010^{-2} \\
5.010^{-2} \\
1.010^{-1} \\
5.0 \times 10^{-1} \\
1.0\end{array}$ & $\begin{array}{l}9.98710^{-4} \\
4.99810^{-3} \\
1.010^{-2} \\
4.93610^{-2} \\
9.97810^{-2} \\
4.95710^{-1} \\
1.0\end{array}$ & $\begin{array}{c}99.87 \\
99.96 \\
100.00 \\
98.72 \\
99.78 \\
99.14 \\
100.00\end{array}$ & $\begin{array}{c}99.84 \pm 0.83 \\
6 \\
0.64 \\
0.32 \\
0.83\end{array}$ \\
\hline $\begin{array}{l}\% \text { Mean } \pm \mathrm{SD} \\
\mathrm{n} \\
\text { Variance } \\
\% \mathrm{SE} \\
\% \mathrm{RSD} \\
\text { t-test } \\
\text { F-test }\end{array}$ & \multicolumn{3}{|c|}{$\begin{array}{c}99.68 \pm 0.48 \\
7 \\
0.23 \\
0.18 \\
0.48 \\
0.435(2.201)^{*} \\
2.78(4.39)^{*}\end{array}$} & \\
\hline
\end{tabular}

Table 5: Comparative analytical results relevant to the terms of linear concentration range and detection limit between the proposed SIA-CL injection and other reported methods

\begin{tabular}{|l|c|c|c|}
\hline \multicolumn{1}{|c|}{ Method } & $\begin{array}{c}\text { Linear range } \\
\left(\mu \mathrm{g} \mathrm{mL}^{-1}\right)\end{array}$ & $\begin{array}{c}\mathrm{LOD} \\
\left(\mu \mathrm{g} \mathrm{mL}^{-1}\right)\end{array}$ & Reference \\
\hline Proposed SIA-CL injection & $0.0001-0.1$ & $3.3 \times 10^{-5}$ & - \\
HPLC-UV detection & $70-130$ & - & {$[2]$} \\
HPLC-Charged aerosol detector & $0.4-0.6$ & - & {$[3]$} \\
HPLC-Fluorescence detection & $0.002-0.08$ & - & {$[4]$} \\
GC-Flame ionization detection & $0.971-1.789$ & 0.437 & {$[8]$} \\
Spectrophotometry & $4-12$ & - & {$[9]$} \\
Spectrophotometry and & $5-70$ and & 0.05 & {$[10]$} \\
spectrofluorimetry & $0.02-0.2$ & & \\
& & & \\
\hline
\end{tabular}

The obtained results were calculated in terms of mean percentage recoveries values. The calculated $\%$ recovery was $99.15 \pm 0.6$.

3.7.5. Precision

The precision of the proposed SIA-CL method was tested in the terms of intra-day and inter-day. The studies were carried out by repeating the determination to nine replicates. The calculated $\%$ RSD values were $1.4 \%$, for determination of memantine hydrochloride in (Ravemantine ${ }^{\circledR} 10 \mathrm{mg} /$ tablet). The above $\%$ RSD value is less than $2 \%$ indicating good precision.

\subsubsection{Robustness}

The robustness of SIA-CL method for determination of memantine hydrochloride was investigated by introducing small changes on method parameters. In the proposed study the robustness of the method was carried out by changing the $\mathrm{pH}$ of the test solution $10 \pm 1$ using $1.0 \mathrm{~mol} \mathrm{~L}^{-1}$ sodium hydroxide or hydrochloric acid and the percentage recoveries were calculated.

The calculated $\%$ recovery for the proposed method was $99.26 \pm 0.9$. The obtained results were closely in agreement with those obtained from standard drug solutions. 


\section{CONCLUSION}

A sequential injection CL method for the quantitative determination of memantine hydrochloride was successfully developed. The method is based on the reaction of luminol with hydrogen peroxide in alkaline medium of $\mathrm{pH} 10$. The CL intensity is substantially enhanced by memantine hydrochloride. The SIA injection system showed good stability and satisfactory detection limit. Also, the proposed method offers advantages of simplicity, reproducibility, short response time and high sensitivity for determination of memantine hydrochloride whether being in pure form and its dosage forms. The employment of automated SIA-CL technique was significantly improved the precision of CL detection and control the consumption of samples and reagents. No interference was found from the additive compound to memantine hydrochloride dosage forms.

\section{ACKNOWLEDGMENTS}

This project was supported by King Saud University, Deanship of Scientific Research, College of Science Research Center.

\section{REFERENCES}

1. B. Reisberg, R. Doody, A. Stöffler, F. Schmitt, S. Ferris, H.J. Möbius, New Engl. J. Med. 348,1333, (2003)

2. B. Narola, A.S. Singh, P.R. Santhakumar, T.G. Chandrashekhar, Anal. Chem. Ins. 5, 37, (2010)
3. L. Rystov, R. Chadwick, K. Krock, T. Wang, J. Pharm. Biomed. Anal. 56, 887, (2011)

4. A. Zarghi, A. Shafaati, S.M. Foroutan, A. Khoddam, B. Madadian, Sci. Pharm. 78, 847, (2010)

5. A.A. Almeida, D.R. Campos, G. Bernasconi, S. Calafatti, F.A.P. Barros, M.N. Eberlin, E.C. Meurer, J. Pedrazzoli, J Chromatogr. B 848, 311, (2007)

6. R.K. Konda, B.R. Challa, B.R. Chandu, K.B. Chandrasekhar, J Anal Method Chem. 2012,1, (2012)

7. H.J. Leis, W. Windischhofer, Microchim. Acta, 179, 249, (2012)

8. S.A. Jadhav, S.B. Landge, N.C. Niphade, S.R. Bembalkar, V.T. Mathad, Chromatogr. Res. Int. 2012, 1, (2012)

9. V. Jagathi, B. Anupama, P. Saipraveen, G.D. Pao, Int. J. current. Pharm. Res. 2, 17, (2012)

10. A.P. Rani, S. Bhawani, C. Nagalakshmi, C.B. Sekaran, Chem. sci. J. 2012 $60,(2012)$

11. K. Michail, H. Daabees, Y. Beltagy, M. Abdeklkhalek, M. Khamis, Int. J. Pharm. Pharm. Sci. 3, 180, (2011)

12. ICH Technical requirements for registration of pharmaceuticals for human use, Complementary Guidelines on Methodology. Washington, DC, 13, (1996)

13. J.C. Miller, J.M. Miller, Statistics for Analytical Chemistry $3^{\text {rd }}$ ed. Ellis Horwood-Prentice Hall, Chichester, (1993). 